\title{
Arbor
}

\section{Desde los materiales tradicionales a los nuevos materiales y métodos aplicados en la conservación de obras de arte}

\section{Pilar Sedano Espín}

Arbor CLXIX, 667-668 (Julio-Agosto 2001), 577-589 pp.

Una de las labores encomendada a los técnicos en conservaciónrestauración es la realización de los tratamientos necesarios para intentar conservar las obras de arte y que estas puedan ser conocidas por generaciones posteriores. Estos tratamientos han variado mucho durante la historia de la restauración.

Podríamos decir que ya los griegos protegían las maderas de sus construcciones para su mejor conservación y desde estos ungüentos a los actuales sistemas de consolidación se han desarrollado muchas técnicas.

Los criterios de intervención también han variado muchísimo. Hace sólo 40 años se pensaba en tratamientos muy intervencionistas que invadían toda la obra, (pintura, preparación y soporte) mediante el adhesivo para dejarlos totalmente impregnados y que resistieran el máximo tiempo posible pensando que así el tratamiento duraría más años.

Actualmente se ha pasado a la idea de la mínima intervención y al tratamiento puntual dándole mucha más importancia a las condiciones en que se almacena o expone la obra, medidas climáticas y de luz, insistiendo en la conservación preventiva para evitar someter a las obras de arte a cambios bruscos que puedan producir daños en sus materiales constitutivos, evitando así intervenciones innecesarias.

Desde la creación del departamento de Conservación en el año 1991 se ha desarrollado una línea de investigación sobre nuevos materiales, tales como adhesivos y materiales de acabado, pigmentos o 
barnices, soportes etc., dada la complejidad que supone el tratamiento de las obras contemporáneas.

Los materiales más usuales empleados desde hace años en la obra clásica son las colas de pasta y colettas de influencia italiana o las ceras de influencia anglosajona. En España hay una mayor influencia de las técnicas italianas aunque en casos concretos se utilizan los métodos anglosajones. También tenemos que citar la creación del Instituto de Conservación y Restauración en los años 60 en Madrid, que traerá a España la influencia en métodos y criterios de trabajo del IRPA de Bruselas.

Siguiendo la escuela italiana las fijaciones de color en las pinturas, ya sea sobre soporte de lienzo o tabla, se realizan habitualmente con adhesivos naturales como las colettas, cola fuerte también llamada cola de huesos, que normalmente se suministra en forma de grumos o de polvo granulado. Esta cola se disuelve en agua y se le añade una proporción de melaza o miel de caña para dar más elasticidad a la mezcla.

También en España se utiliza la cola de conejo, que se obtiene de desperdicios de animales pequeños (piel, huesos y tejido muscular) y se suministra generalmente en grumos o pastillas; y la cola de pescado, que generalmente se fabrica con restos de espinas y restos de pescado, se suministra en láminas y en polvo. Otra variedad de la cola de pescado es la cola de esturión, esta variedad se hace con las vejigas natatorias del esturión. Es una cola de mejor calidad. Últimamente se puede encontrar en el mercado más especializado una cola de pescado ya preparada líquida para emplearla en frío.

La coletta o colas se aplican sobre la pintura y sobre ella se coloca un papel. Actualmente se utilizan papeles de diferentes texturas, sobre todo los papeles japoneses, secando la cola y haciendo presión sobre la pintura levantada mediante espátulas metálicas calientes.

Las limpiezas de las obras generalmente se hacen con fórmulas de combinación de disolventes líquidos volátiles, en general compuestos sencillos de bajo peso molecular. La mayor parte de los compuestos que forman parte de las fórmulas de limpieza para pinturas y policromías, son líquidos orgánicos volátiles que se combinan entre sí para formar disoluciones. Para la eliminación de repintes muy duros, óleos o aglutinantes con huevo o de barnices excesivamente duros, se pueden utilizar geles o mezclas menos volátiles que prolongan el tiempo de contacto de los disolventes sobre la zona a tratar mediantes algún vehículo como compresas o cargas.

Las fórmulas para las limpiezas que se han venido utilizando en España provienen en general del Restauro de Roma y del IRPA de Bruselas. 
Cuando es necesario el refuerzo del soporte por mal estado de la tela, desgarros o pérdidas del mismo, se realizan reentelados con telas de lino y cola de pasta (colettas más harina). También en ocasiones estos reentelados se hacían por craquelados muy acusados o deformaciones fuertes de la pintura para evitar la memoria plástica, es decir la recuperación de las deformaciones después de acabado el tratamiento.

En los reentelados con cola de pasta podemos distinguir dos métodos: el italiano y el español.

Los dos utilizan la cola de pasta pero con diferencias notables. El italiano utiliza la pasta más espesa, en su formulación se incorpora menos agua, y se aplica en frío sobre la tela nueva y vieja del cuadro original, una vez que este último esta limpio y unidos todos los desgarros y rotos mediante estucos para evitar que la pasta penetre en la preparación y pintura. También se suele dar un agente aislante como barniz o paraloid en muy baja proporción sobre la tela original antes de aplicar el adhesivo.

El calor se aplica muy suave sobre la pintura protegida con papel y se airea constantemente para secar el adhesivo.

El sistema antiguo español difiere con el anterior en que la pasta o adhesivo se da caliente tanto en la tela nueva como en la original y se utiliza esta misma pasta pasando a través de la preparación desde la tela para fijar el color al mismo tiempo que realizamos el reentelado, con la consecuencia de que toda la obra queda impregnada con el adhesivo de una manera irreversible. El adhesivo se seca con bastante calor ya que se aprovecha la humedad de la pasta y el calor para fijar los craquelados de la pintura.

La influencia anglosajona sin embargo apenas entra en España. Raramente se utiliza la cera como adhesivo y sólo por motivos de clima excesivamente húmedo, por ejemplo en obras que permanecen en el norte de España. En los reentelados con cera, al igual que en los de la cola de pasta españoles, la pintura queda impregnada con el adhesivo de manera irreversible.

Las ceras han sido repetídamente utilizadas en el campo de la conservación y restauración de obras de arte. En pintura de caballete como adhesivo para reentelados, parches y bordes, normalmente mezclada con resinas. También se ha utilizado la cera como consolidante de la madera y como agente protector e impermeabilizante de metales, cueros etc. Generalmente se han empleado dos tipos de ceras y a veces mezclas de las mismas.

La cera microcristalina que es un tipo especial de la parafina y como ella proviene del petróleo. Esta formada por hidrocarburos 
saturados de cadena larga y como propiedades podemos reseñar que es más flexible que la parafina y de mayor poder adhesivo. Es de color blanco y su punto de fusión está entre los $84-90^{\circ} \mathrm{C}$. Se suministra generalmente en pastillas o en solución al $40 \%$ en White Spirit.

La más tradicional empleada es la cera de abeja. La cera de abeja, químicamente es muy estable y conserva durante largo tiempo sus propiedades. Es prácticamente insoluble en agua y soluble en hidrocarburos aromáticos, clorados y en etanol en caliente. Generalmente se presenta libre de impurezas y en diferentes formas de presentación, como cera virgen en panes, decolorada o blanca en grumos, en bolitas, etc.

En pintura de caballete, como adhesivo de reentelado, la cera se aplica en las dos telas y se plancha con bastante calor desde la tela nueva colocando la pintura hacia abajo. Para la forración del cuadro con la cera, previamente se protege la pintura con cola de almidón aplicada con papeles y refuerzos de tiras de papel en los bordes que hacen el efecto de tensores.

La cera tiene además el problema de que engrasa la preparación y los colores alterando su tonalidad. También en Bélgica y norte de España se ha utilizado la cera disuelta en esencia de trementina para fijar el color en pinturas de tabla o lienzo. En el norte de Europa el uso de la cera es más generalizado ya que muchos pintores incorporan ceras en las preparaciones de sus pinturas.

En general, en los reentelados con cera se protege la parte de la pintura con almidón como hemos explicado, para crear una barrera impermeable al paso de la cera sobre la superficie pictórica, pero esto no impide que toda la preparación quede impregnada y que si la pintura tiene fisuras el adhesivo pueda salir a la cara anterior.

Para muchos reentelados con cera se utilizaba la mesa caliente con mantas de poliéster, que aumentan la presión sobre la capa pictórica, por lo que ésta pierde los empastes o pinceladas quedando una superficie totalmente plana y dura.

A partir de mediados de los años 70 comienzan a utilizarse adhesivos sintéticos como el Mowilih. Los poliacetatos de vinilo (PVA) son materiales termoplásticos producidos por la polimerización del acetato de vinilo. Se emplean en disolución en disolventes orgánicos no polares o con más frecuencia en emulsión acuosa o hidroalcohólica. Los polialcoholes vinilos (PVAL) son termoplásticos producidos por la hidrólisis de los acetatos de polivinilo. Se aplican en solución acuosa como adhesivos. Y un buen número de lienzos, sobre todo los más actuales, se han reentelado con este adhesivo que pasados los años, alrededor 
Desde los materiales tradicionales a los nuevos..........

1. Vista fachada principal del Museo Reina Sofía

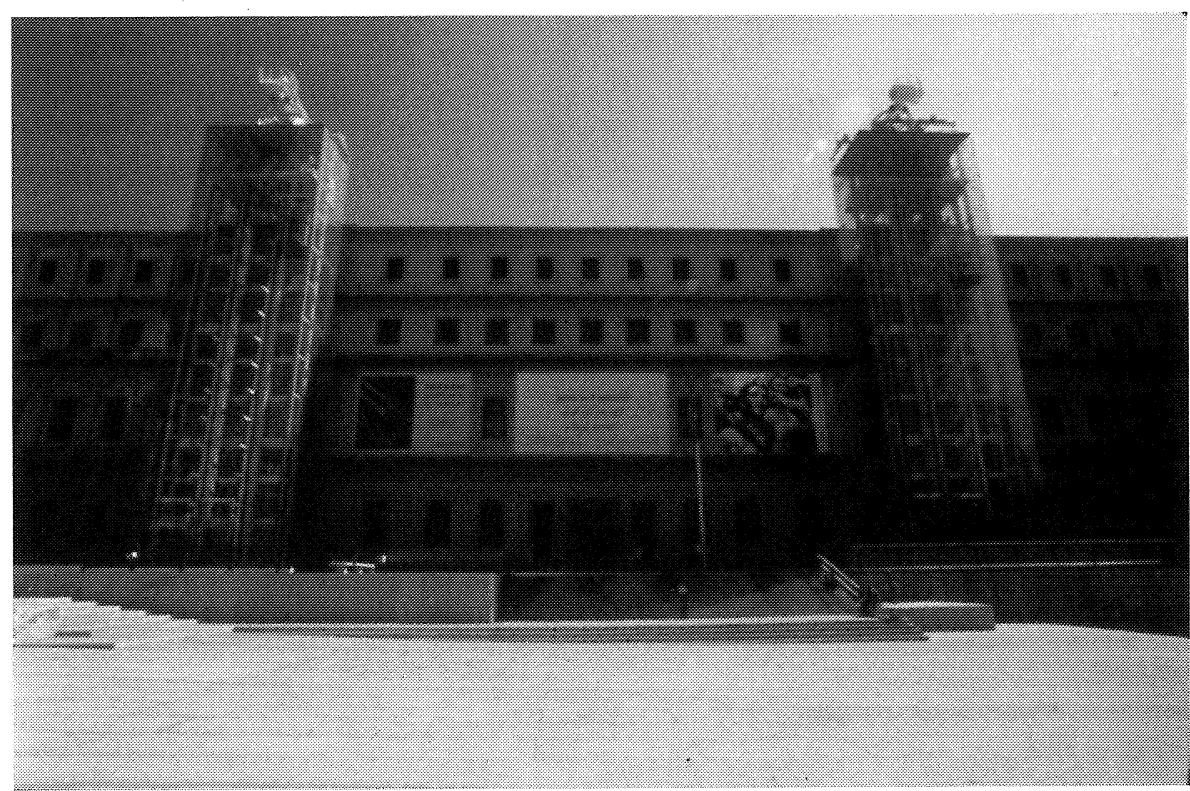

2. Torre del muelle de carga y montacargas del Museo Reina Sofía

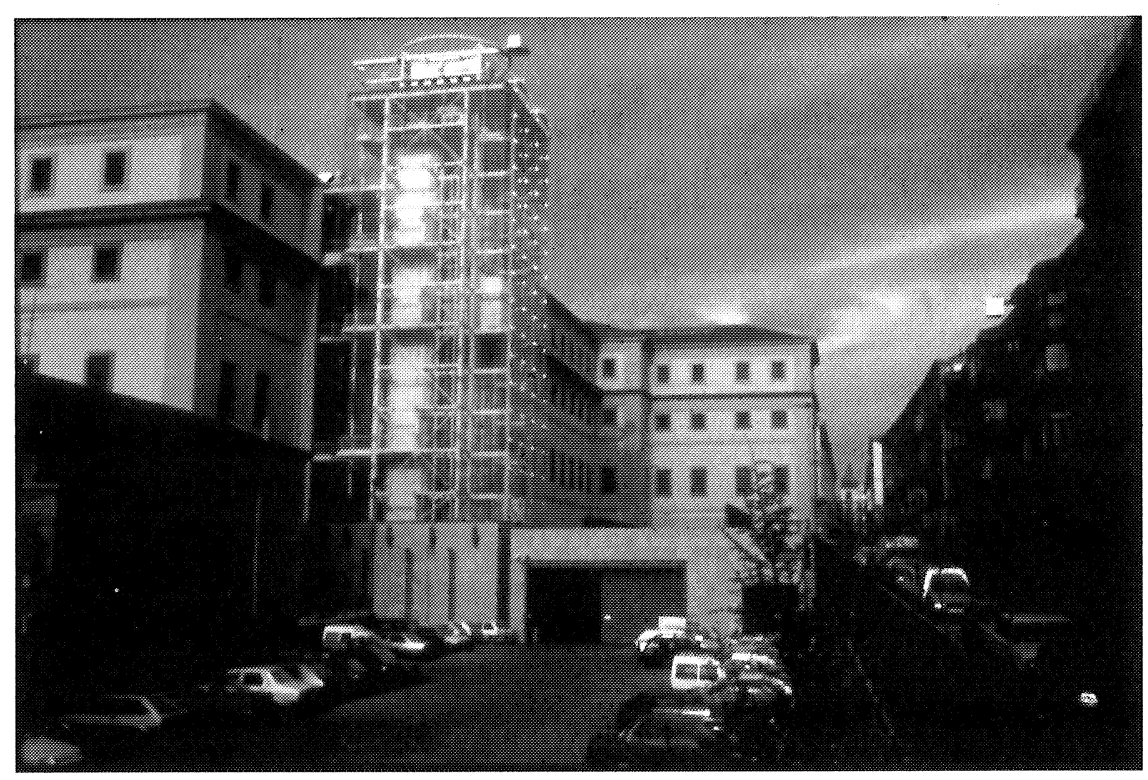


de 10 e incluso menos, se endurece y parte con cualquier manipulación. Además si el reentelado se ha realizado sin aislar la tela original, éste penetra hasta la capa pictórica pudiéndose apreciar el adhesivo en las zonas de colores oscuros azules, negros y pardos. Se han utilizado también para la colocación de bandas o bordes.

Con la revisión de los criterios en las intervenciones de restauración de los últimos años, estos métodos prácticamente no se utilizan en las maneras más extremas, pues como adhesivos bien aplicados, las colettas, colas de conejo o colas de pasta tienen buenos resultados en obras anteriores al S.XIX, así como los adhesivos resinosos, siempre que se utilice de manera local y sin la impregnación total de la obra.

En los años 80 se produce una reordenación de museos y colecciones estatales que conlleva el traslado del antiguo Museo Español de Arte Contemporáneo situado en un edificio en la Ciudad Universitaria al edificio de Savatini en la Glorieta de Atocha.

El edificio Savatini fue mandado construir por el Rey Carlos III y desde entonces hasta el 1965 albergó el Hospital de Madrid.

En 1980, la Dirección General de Bellas Artes encarga al arquitecto Antonio Fernández de Alba su restauración en una primera fase, acabando su adecuación como Museo los arquitectos Vázquez de Castro y José L. Iñiguez. El 31 de octubre de 1990 se inaugura como Museo Nacional de Arte Contemporáneo.

Las obras finalizadas en 1990 supusieron su habilitación para uso museístico, la dotación de infraestructura técnica (control de temperatura y humedad, seguridad, etc.) en todo el edificio y la construcción de un muelle de carga, con un montacargas suficiente para obras de gran formato y peso, que comunica la entrada de obras con los almacenes, salas de exposiciones y el Departamento de Conservación-Restauración.

En la remodelación del edificio se dedica un espacio y dotación importantes para la creación de un Departamento de ConservaciónRestauración que va ser uno de los más modernos.

Una vez inaugurado en 1992, desde el mismo se está trabajando en una línea de investigación de nuevos materiales, tanto utilizados para tratamientos como presentes en las obras, como adhesivos, soportes, etc. y la manera de aplicación en los citados tratamientos dada la complejidad que supone la restauración de las obras contemporáneas.

En general se puede pensar que las obras modernas no deberían tener problemas al ser obras de reciente creación, pero al contrario que las obras clásicas plantean serios problemas debido a los propios materiales de la obra o filosóficos en su creación, también el abandono 
3. Salas del Museo. Exposición permanente

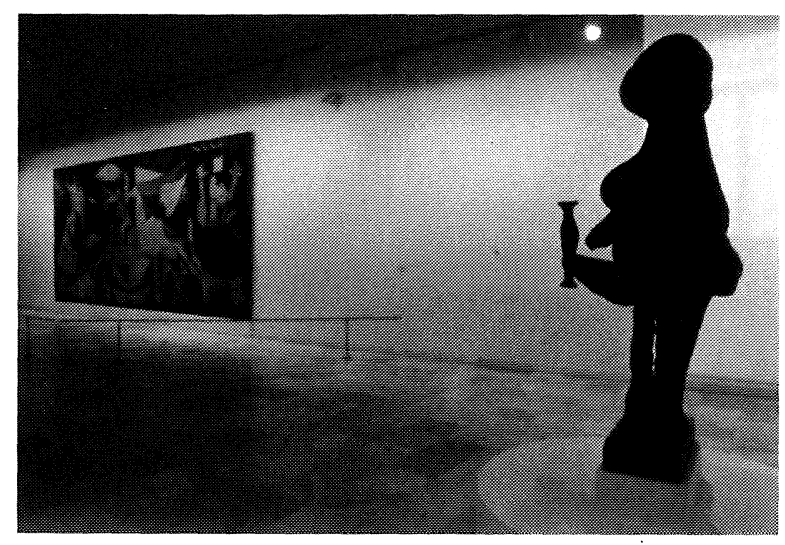

4. Salas del Museo. Exposición permanente

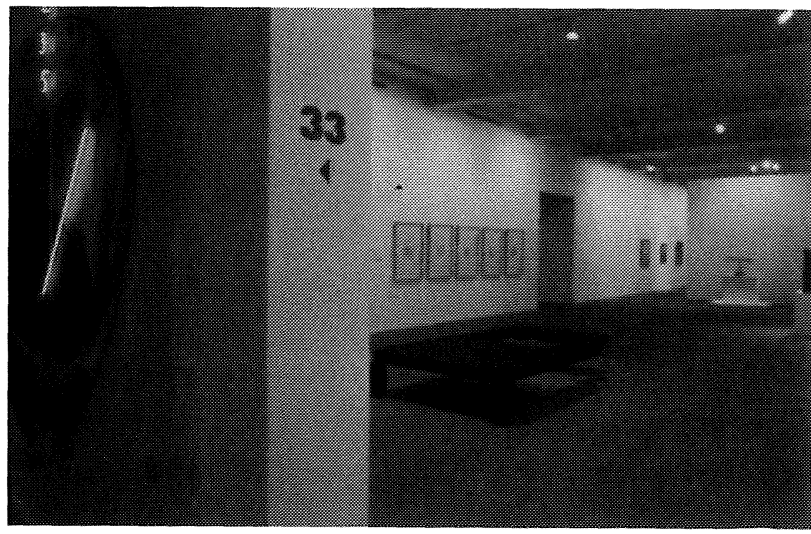

5. Salas del Museo. Expoxición permanente

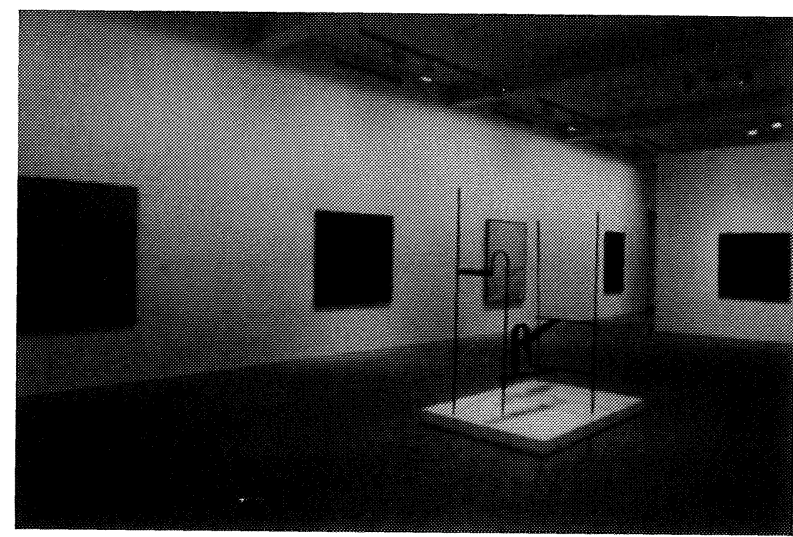


que han sufrido muchos de ellos, por motivos políticos o simplemente porque no se les daba ningún valor en su época. Por estas causas la problemática del arte contemporáneo es bastante compleja.

Intentando crear bases de información que nos ayuden a solucionar los problemas de estas obras, en el año 88 junto con la Diputación de Álava creamos los modelos de encuestas para los artistas, en los que intentamos que nos especifiquen el mayor número de datos sobre la creación de sus obras, materiales, ideas, etc.

Así mismo, se comienza a documentar y estudiar desde los laboratorios de química y Rayos X las obras que componen los fondos del Museo.

La diversidad de materiales concurrentes en una sola obra, los aspectos estéticos intencionados que el artista quiere plasmar, la ausencia de protecciones y barnices, cantidades insuficientes de aglutinantes o soportes inadecuados, obligan a estudiar nuevos materiales para sus tratamientos.

Entre los adhesivos tradicionales se utiliza la cola de pescado en proporciones muy bajas. Al ser una cola más transparente evita la formación de manchas o cercos, así mismo la manera de aplicarla es sin papel y solamente en la grieta o craquelado de la pintura y activando su penetración mediante mesas de succión y secándola puntualmente con aire caliente o rayos infrarrojos.

Otros adhesivos que tienen buenos resultados son los derivados de la celulosa empleados en los tratamientos de obras con soporte celulósico.

Adhesivos semisintéticos derivados de la celulosa es decir, ésteres de la celulosa solubles en agua y disolventes polares como los alcoholes simples que se emplean como adhesivos para papel y en técnicas acuosas como temples. Actualmente en pintura contemporánea los más utilizados son:

La metilcelulósa, soluble en agua fría, forma películas flexibles químicamente inertes y resistentes a microorganismos.

La carboximetilcelulosa es soluble en agua hasta $50^{\circ} \mathrm{C}$ e insoluble en etanol, acetona y eter.

El almidón es un polisacárido natural se ha utilizado en reentelados en frío en pinturas contemporáneas, sobre todo con soporte de papel o textiles muy finos. También se emplean cuando son pinturas que no admiten calor pero que tienen deformaciones importantes con memoria plástica, al adherirlos a una nueva tela evitamos su nueva aparición. El almidón se emplea tradicionalmente para tratamientos de obras con soporte celulósico, sobre todo en Japón y se probó en pinturas al temple sobre sargas en el IRPA de Bruselas. 
Desde los materiales tradicionales a los nuevos..........

6. Vista general. Departamento de Conservación-Restauración

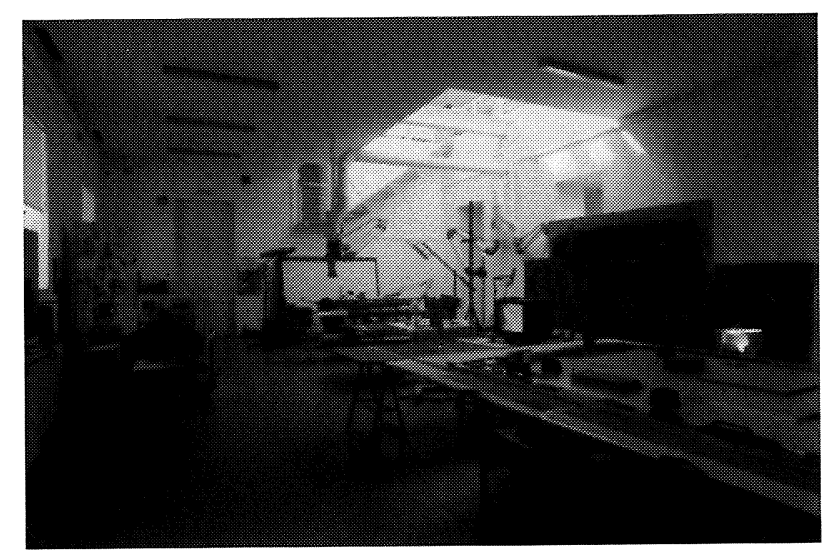

7 y 8. Eliminación de manchas mediante capilares y mesa de succión
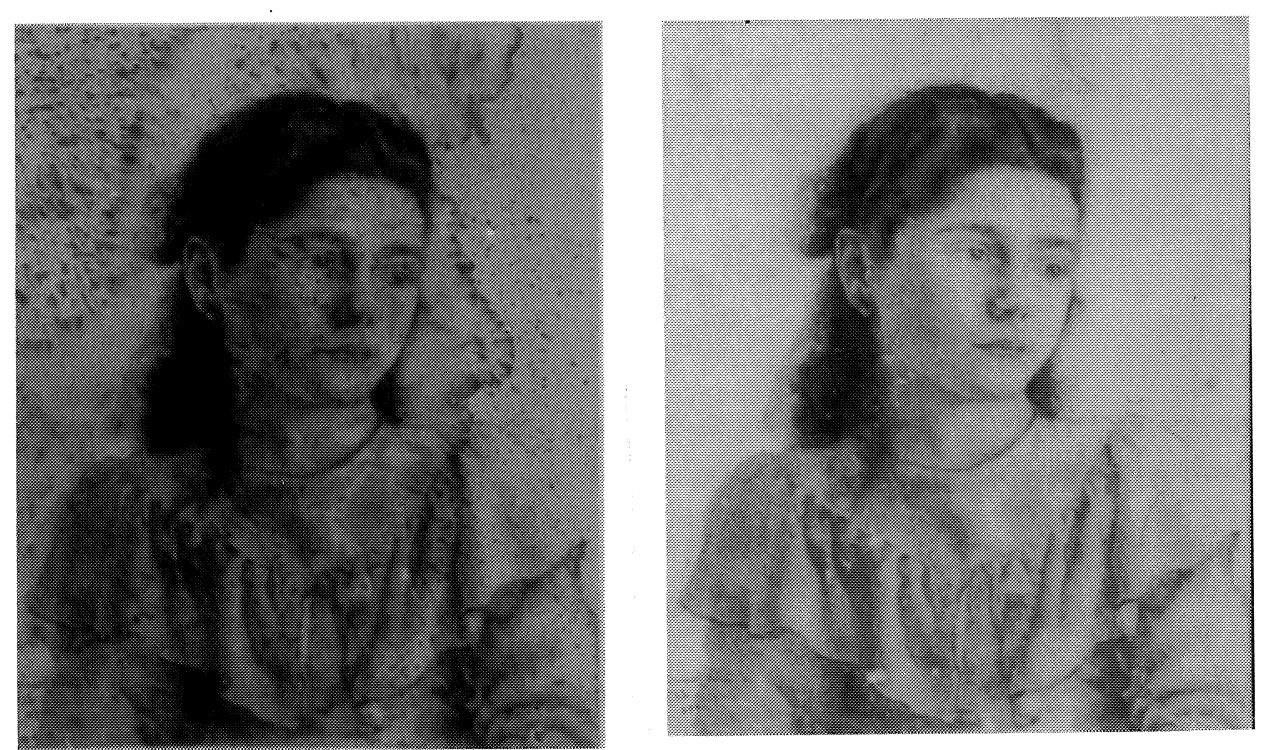
El Klucel (Hidroxypropilcelulosa), se presenta como polvo soluble en agua y disolventes polares orgánicos como alcoholes metilico, isopropílico, etc., es extremadamente flexible, y no lleva en su composición plastificantes. En caso necesario se puede aumentar su poder adhesivo con la adición de pequeñas cantidades de adhesivos acrílicos. Tiene también la ventaja de no dejar manchas ni cercos y es muy transparentes.

Para superficies más gruesas y cuadros con grandes empastes o mezclas de materiales, arenas, pigmentos inertes etc., se pueden utilizar acrílicos como Plexisol, resina acrílica, que se trata de un polímero a base de metacrilato de butilo en solución. El Plexigum, etil metacrilato en solución al $33 \%$ en etanol. es una resina incolora de baja viscosidad, que se usa como fijativo.

El Plextol, a base de acrilatos y metacrilatos de etilo y metilo, cuya presentación suele ser como emulsión, es un líquido blanco de aspecto lechoso. Es soluble en hidrocarburos aromáticos. Forma una película transparente incolora y flexible.

El Primal es una resina acrílica termoplástica, se presenta como emulsión de aspecto lechoso y color blanco con $\mathrm{pH}$ 8,5-9,1. Dispersable a cualquier proporción de agua y otros sistemas acuosos. Generalmente estos adhesivos se aplican inyectados puntualmente.

En la actualidad estamos estudiando las aplicaciones con otro tipo de adhesivo, el Funori, también conocido como FUNORAN. Es un mucílago extraído de tres tipos de algas marinas rojas de la familia de las GLOIOPELTIS: la TENAX, la COMPLANATA y la FURCATA. Es un polisacárido con unidades de galactosa y algunos sustituyentes sulfato. Se utiliza en Japón desde el año 1600 como agente espesante en el proceso de estarcido del KATAZOME o sistema tradicional de tintes, y como adhesivo en la fabricación del papel.

Normalmente se presenta en láminas finas con las fibras de las algas deshidratadas. Estas pueden presentar impurezas de origen marino, por ello se recomienda filtrar bien previamente con agua destilada.

La referencia de este adhesivo proviene de los técnicos del Museo de Arte Moderno de Nueva York que lo estaban utilizando desde hacía tiempo en restauración de papel y últimamente estaban probando en sus pinturas la aplicación del mismo.

Los reentelados o refuerzos de soportes no se realizan habitualmente y sólo en casos puntuales en los que no existe otra solución menos intervencionista. En reentelados, los adhesivos que mejor han funcionado en los tratamientos de arte contemporáneo han sido el Beva Film o Beva Nieve y adhesivos acrílicos como el Lascaux. En los dos casos, antes de proceder al reentelado o unión de las dos telas, nueva 
Desde los materiales tradicionales a los nuevos..........

9. Tratamiento puntual de fijación de color con la ayuda de la mesa de succión

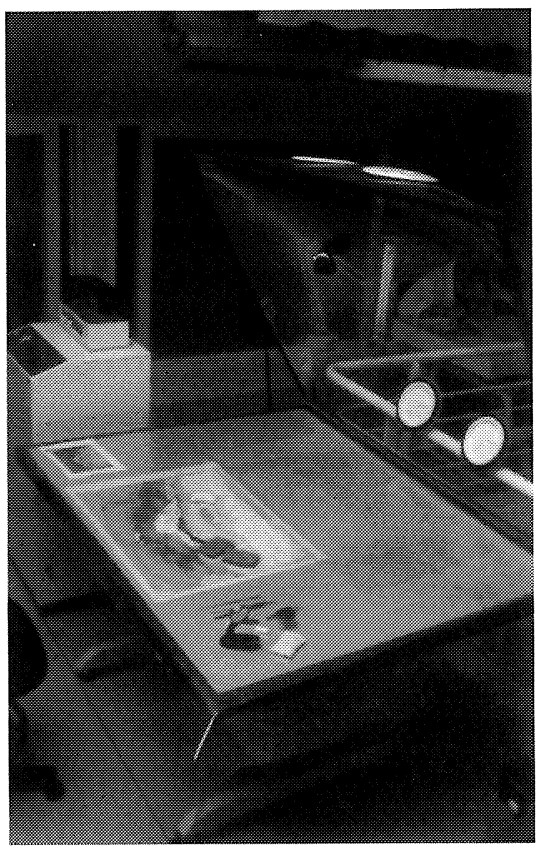

11 y 12. Tratamiento de fijación de color con el adhesivo Funori

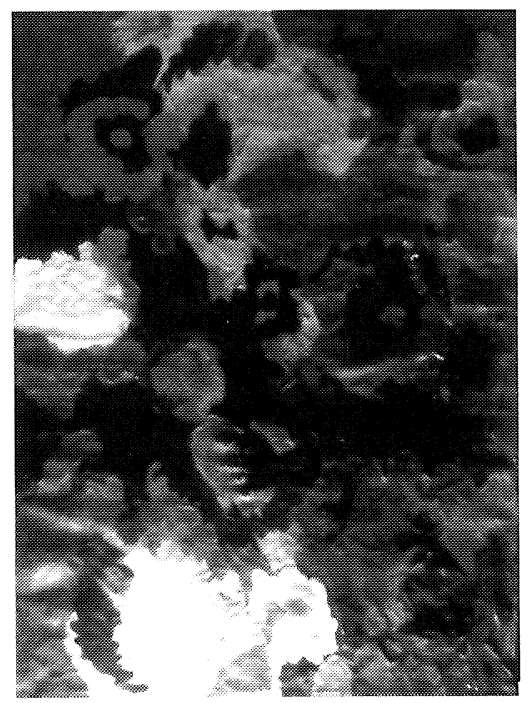

10. Funori
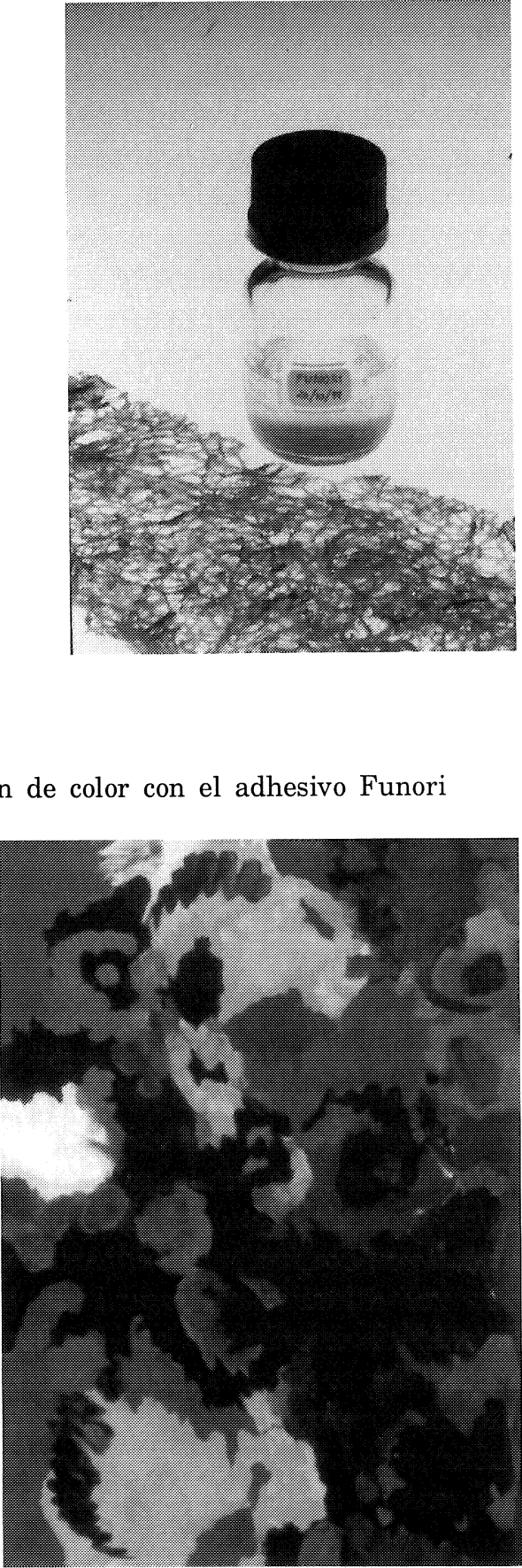
y original, se fija el color si es necesario con otro adhesivo más suave que hayamos previamente probado y se eliminan las deformaciones del soporte, quedando el lienzo y pintura perfectamente preparados.

En el caso de los reentelados con Beva se puede aplicar disuelta en tolueno y se aplica con spray sobre la tela nueva, dejando secar y evaporar el disolvente, quedando sólo unas pequeñas líneas semejantes a hilos que después activaremos con calor en la mesa de baja presión. La mesa se calienta a la temperatura de fusión de la Beva durante unos segundos. Anteriormente habremos colocado la tela nueva y encima el lienzo cubierto con Nylon Dartex. Este nylon aguanta altas temperaturas y se amolda perfectamente a los empastes, pinceladas o materiales de diferentes texturas que presenta la obra, sin oprimirlas. Además es transparente por lo que en todo momento podemos controlar cualquier pequeña alteración.

Una vez disuelta la Beva se enfría la mesa dejándola sólo con la presión hasta que ésta quede totalmente seca. De esta forma al ser la cantidad de adhesivo tan pequeña y el tiempo de fusión corto impedimos que éste penetre más alla de la tela original. El caso de la Beva film es similar. Se aplica en la tela nueva y se procede de la misma forma que en el caso anterior.

Para utilizar los adhesivos sintéticos se disuelven en el medio apropiado y se pulverizan sobre la tela nueva, se dejan secar (es decir evaporar el disolvente). En el momento del reentelado se activa nuevamente para colocar la tela original en contacto con la nueva siempre con la pintura hacia arriba, igualmente con presión controlada hasta que el adhesivo seque totalmente. Esta operación se realiza en frío. Otros reentelados que se emplean con precaución, dependiendo del tipo de pintura, pueden ser los reentelados con almidón. También en frío y con presión. Lo más habitual es emplear reentelados flotantes o protecciones traseras.

Las limpiezas de las obras contemporáneas suelen hacerse mecánicamente, es decir, mediante gomas, de diferentes durezas, brochas, aspiración suave, jabones neutros.

En casos puntuales se pueden utilizar disolventes muy volátiles, de poca penetración, sobre todo cuando hay que eliminar barnices o retoques de antiguas restauraciones.

Referente a obras sobre soporte celulósico llevamos probando desde hace años los métodos de limpieza, combinando la succión con pequeños capilares que puntualmente colocan la gota del disolvente sobre la mancha. La succión de la mesa hace que el disolvente no se expanda evitando que el disolvente provoquen los temidos cercos. 
Otra técnica de limpieza para las manchas, sobre todo las provocadas por restos de cintas adhesivas utilizadas en los montajes para enmarcaciones, es el sistema de arcillas como medio de aplicar los disolventes.

Para la eliminación de las deformaciones en soportes celulósicos estamos utilizando la mesa de succión. Una vez humectado el soporte en cámaras de ultrasonido, se coloca en la mesa de succión para terminar el secado. Con este método se eliminan las deformaciones, incluso de dibujos a pastel, sin necesidad de usar fijativos ya que se eliminan los lavados, la humedad directa y la colocación de pesos y prensas sobre la obra.

También este sistema lo empleamos para la eliminación de deformaciones en los soportes de tela de pinturas. En el caso de las pinturas utilizamos la mesa de baja presión en frío, en donde la humedad no se aplica directamente sobre el soporte sino sobre superficies, como secantes, que se colocan en contacto con él.

Con la aplicación de estos métodos perseguimos que la intervención necesaria sea mínima. Sólo en casos extremos de grandes daños se estudia una intervención mayor, siempre sopesada con los resultados que pueda tener.

Asimismo intentamos respetar todos los aspectos originales de las obras: texturas, empastes y acabados, ya que son fundamentales sobre todo en la obra contemporánea.

Por último, hay que remarcar la importancia de la conservación preventiva, en la que debemos implicar al resto de profesionales, que tienen la responsabilidad de conservar el Patrimonio Cultural.

Proyectos patrocinados por el ICROM y otros organismos internacionales están elaborando programas con el fin de involucrar a profesionales, desde los directores de Museos, coordinadores, conservadores, comisarios, diseñadores de exposiciones, responsables de seguridad y mantenimiento, así como a empresas de montajes y transportes de Obras de Arte para poder unificar unas normas y recomendaciones que nos ayuden a la práctica día a día de la Conservación Preventiva. Aspecto que en los Museos de Obras Contemporáneas tiene una mayor dificultad debido a la necesidad de entendimiento y compresión de la obra por el público.

\section{Bibliografía}

Marisa Gómez. «Examen La Restauración científico aplicado a la conservación de obras de arte».

The use of Funori as a consolidant for Matte Paint Hiroko. Kariya a Rachel Danring, Brodklyn Museun of Art. Cuadernos de Productos RCM. 